\title{
Teaching Residents to Treat Substance Use Disorders: Overcoming 10 Common Patient-Perceived Barriers to Outpatient Treatment Engagement
}

\author{
Stephanie M. Davidson ${ }^{1} \cdot$ Hilary S. Connery ${ }^{2,3} \cdot$ Shelly F. Greenfield ${ }^{2,3} \cdot$ Kevin P. Hill ${ }^{3,4}$ \\ Received: 2 September 2020 / Accepted: 8 December 2020/Published online: 13 January 2021 \\ (C) Academic Psychiatry 2021
}

Patients with substance use disorders (SUDs) are frequently seen in outpatient settings; 40 to $60 \%$ of patients in mental health treatment and $36 \%$ in primary care clinics have co-occurring SUDs [1-3]. Although most patients with SUDs are not treated by addiction specialists, education on treating patients with SUDs varies widely across residencies [4, 5]. Patients with SUDs pose challenges to trainees due to the relapsing and remitting nature of these illnesses and the stigmatization of these patients [6]. Furthermore, patients with SUDs are believed to be more difficult to treat and more likely to elicit negative countertransference than patients with other psychiatric disorders [7, 8]. Working with this population early in training, with appropriate guidance, can support residents in gaining expertise and competence in treating these patients and encourage them to continue to treat them as trainees progress to independently practicing physicians [9].

In this paper, we identify common barriers patients with SUDs perceive hinder them from engaging in treatment. We propose a framework, building upon motivational interviewing (MI) theory, to help trainees prepare for and respond to these barriers when they arise in treatment, improving trainee confidence and competence in these settings $[10,11]$. In addition, alternative treatment platforms, e.g., telehealth, which has become more

Stephanie M. Davidson

davidsons1@chop.edu

1 Children's Hospital of Philadelphia, Philadelphia, Pennsylvania, USA

2 McLean Hospita, Belmont, Massachusetts, USA

3 Harvard Medical School, Boston, Massachusetts, USA

4 Beth Israel Deaconess Medical Center, Boston, Massachusetts, USA accessible during the COVID-19 pandemic, may overcome certain patient-perceived barriers when clinically appropriate [12].

\section{Patient Perception of Barriers to Substance Use Disorder Treatment}

Patients often cite barriers to their treatment, which may reflect the patient's ambivalence about making changes in their substance use. This ambivalence is an important treatment target, as it hinders the patient's engagement in treatment, perpetuates continued substance use behaviors, and, in turn, worsens prognosis. These barriers are often viewed by the patient and, at times, the clinician as insurmountable reasons the patient is unable to engage in treatment. The trainee may find themselves at a loss for how to address these barriers. While patients may cite these barriers in any level of care, this paper will focus on barriers typically encountered while providing outpatient SUD care.

Understanding the patient's perceived barriers to treatment can help residents advance treatment through discussion, problem solving, and alliance-building. Discussing these barriers, both external (e.g., transportation, work conflicts, childcare needs) and internal (e.g., ambivalence about changing substance use), can be affect-laden and create difficult clinical interactions. Demonstrating an understanding of the patient's perceived barrier(s) and what they signify for the patient helps foster therapeutic alliance, enhances patient engagement and retention in treatment, and ultimately improves clinical outcomes [13, 14]. To work through these barriers, it is critical to utilize a MI approach, practice empathic curiosity, and evoke personal incentives for change, while facilitating behavioral commitments for change $[10,11]$. 


\section{Common Patient-Perceived Treatment Barriers and Frameworks for Addressing Them}

"I have to get back to work."

The patient may recognize the value of the proposed treatment, but attributes their inability to follow recommendations to timing of fixed obligations (e.g., school, work, legal) and/or consequences of missed obligations.

The resident can focus on treatment engagement as a first step to achieving a positive outcome. For example, stating, "While I understand you are concerned about employmentrelated consequences, let's think about how to help your employer understand if you need to take time off for treatment. Also, I wonder what other negative consequences may occur should you not engage in treatment at this time." This is also an opportunity to address the importance of support from colleagues, family, and other institutional structures. It may help to encourage the patient to inquire about policies (time off, sick leave, vacation, etc.), stressing that the patient's work performance would benefit from SUD treatment. Additionally, telehealth platforms may be useful in reducing this barrier, as engaging in virtual outpatient sessions avoids time in transit.

"I have to take care of my family/pets at home."

The patient acknowledges the importance of treatment but perceives treatment as conflicting with other responsibilities. The patient may not have others to assist or may not wish to inconvenience anyone to provide this support.

This barrier provides opportunities to reinforce the importance of support and the necessity of self-care during SUD treatment. SUDs are life-threatening conditions that often require assistance from available supports in the patient's network. Exploring the patient's reluctance to seek support from specific family and friends can help the patient decide how and from whom to seek support. Family and friends may be concerned but also may feel they have tried to help before without a positive outcome, so blanket assurances should be avoided, while actively helping the patient problem solve (e.g., considering telehealth).

"My insurance won't cover that, will it?"

This patient is concerned about financial implications of treatment. Evaluation of this barrier requires the patient and trainee find out what insurance will cover, how to work around limitations (e.g., appealing to the insurance company), and whether this barrier is masking other patient concerns about the recommendations. If the financial barrier is not resolvable, the patient may forgo treatment and cite their insurance as the reason. Rather than allowing systemic barriers to amplify the negative side of the patient's ambivalence, the trainee could assist the patient in finding additional available lower-cost treatment options (e.g., community-based or online programs).

"I can't imagine never drinking again; I have to drink with clients for work and all my friends drink."

The patient views the social norm of drinking as essential to business or social success. It is important to acknowledge that drinking or drug use can play an important role in social circles [15-17]. The resident can educate the patient that this is a common concern and that others have managed to maintain abstinence in similar positions. Substance use has been an integral part of the patient's life, often for many years, while the realization of adverse consequences of substance use may be more recent and difficult to reconcile with the patient's memories of perceived positive effects of use (e.g., relief from anxiety, "high" from intoxication). It is critical to address feelings of loss and grief over lifestyle changes necessary to achieve abstinence and manage a SUD over time [18]. The resident can state, "It feels like all your friends drink, but there are probably some who don't. Can you think of anyone you know who doesn't drink? What could you do instead if you want to socialize without using alcohol or drugs?"

Clients and employers, like friends or family, are often understanding if the patient is honest with them and disclosure may lead to a broader support network. However, it is important to acknowledge that in some settings, it may be difficult or inadvisable to disclose their struggle with SUDs due to potential consequences and social stigma. The patient may benefit from developing and practicing drink or substance refusal skills, e.g., holding a non-alcoholic beverage to defer offers of alcohol and gaining confidence in stating "no thank you" [19].

The resident could present more proximate goals and tasks (e.g., for the following week), while helping the patient evaluate advantages and disadvantages of abstinence. Looking too far ahead may become overwhelming, distracting from tasks needed in the present to initiate or maintain abstinence. The resident can compare this process to taking a long trip, reflecting that it is hard to see objects far away, but these become clear as you move closer. Whether a patient should drink alcohol in a year will be much easier to assess after the year passes.

"Even if I go to residential treatment, my problems will still be here when I get out."

Patients may feel hopeless dealing with the psychosocial stressors that led to use or relapse. Even if the patient acknowledges a short-term higher level of care would be beneficial, 
thinking about chronic psychosocial stressors can be daunting. The resident could explain that while a higher level of treatment will not solve the psychosocial stressors, achieving abstinence can improve their ability to address these stressors upon program completion. They may gain alternative viewpoints, support, and coping skills to manage these stressors without using substances. The trainee can educate the patient on the value of establishing abstinence and review the relationship between early abstinence and prognosis, e.g., achieving 30 days abstinence increases the likelihood of prolonged abstinence [20]. Residential stays can also provide time during which the home environment can be made substance-free.

"I don't want medication. That's trading one drug for another."

This patient may be struggling with stigma about medications for SUDs or psychiatric illnesses, may not understand why prescribed medications should be considered differently than illicit (or even licit) drugs, or may not know why the medication is recommended at all.

This presents an opportunity to educate the patient about medication treatments options for SUDs. The trainee should discuss that medications curb cravings and prevent relapse without inducing intoxication or negative behaviors that accompany substance use, and, in many cases, the proposed pharmacotherapy is time limited. Patients may benefit from a discussion of the multifactorial etiology of SUDs, including a strong heritable component and a relapsing and remitting course like other, less stigmatized, chronic medical illnesses such as asthma, diabetes, and hypertension [21, 22]. The resident might ask if the patient knows anyone with a chronic medical disorder and compare the situations, stating, "would you tell your mother not to take her insulin because she 'should be able to do without it'?"

"This drug is the only thing that helps my anxiety."

This obstacle arises when the resident recommends a regimen without a medication or substance the patient feels was beneficial for them. This conversation should be approached with open-ended questions, determining how that treatment was helpful and allying with the patient on common goals. Problematic behaviors associated with the medication or substance should be raised in a non-judgmental fashion.

The trainee should discuss the intoxication and rebound effects of controlled substances, as well as evidence related to the increased risk of their misuse in patients with SUDs, and the importance of personalized decision making based on safety and clinical need $[23,24]$. The patient may not be aware that while intoxication may transiently help mood or anxiety symptoms, substances can induce mood disorders and contribute to anxiety, depression, or other psychiatric symptoms. The resident also may review alternative non-addictive medications and therapies to help the patient feel heard in finding a safe solution, rather than feeling denied the only "effective" option.

"You keep talking about my drinking, but depression is my REAL problem."

The patient feels another disorder is more important and avoids talking about their substance use. To many patients, depression and anxiety feel more socially acceptable than having a SUD or they perceive that their use of alcohol or drugs is the result of another "underlying" condition and will remit after the other disorder is treated.

The resident should acknowledge the patient's concerns while educating them that many SUDs co-occur with other psychiatric disorders, treating both simultaneously improves the outcomes for each disorder, and substances may worsen underlying psychiatric disorders or induce new psychiatric disorders in patients with no prior history of mental illness [25]. For example, the resident can state, "I see how much you are suffering from your depression. Both depression and SUDs need to be addressed for either to improve. Your antidepressant will be less effective in treating your depression if we do not also address your drinking."

"I know myself better than anyone else does. I can manage this on my own."

This patient is not convinced of the value of the proposed treatment plan or does not feel adequately understood by the resident and feels that their own plan (often with less treatment) will produce the best outcome. The resident should acknowledge the patient knows themself best, but that the resident is trained in the treatment of SUDs. The trainee can utilize a motivational approach to assess the patient's ambivalence, and express concern about the patient's plan. The resident should continue to offer clear treatment recommendations. Offering the patient "a menu" of potential treatment options can be helpful, including offering additional sessions to understand better the patient's thoughts and feelings about taking care of this problem alone. If the patient declines treatment recommendations, the resident can encourage reconsidering them if the patient's plan does not meet their treatment goals after a specified period. The resident can suggest enlisting a supportive family member or friend as part of the contingency plan for added accountability. As always, the trainee may involve their supervisor for support in this discussion

"Others in the treatment group aren't like me."

The patient points to differences in patient demographics, substances used, or severity of illness as interfering with obtaining 
benefit from group treatment. They might add, "I just take a few pain pills, they're shooting fentanyl" or, "Others have lost their jobs to alcohol; I haven't had any issues at work." The resident can point out that common themes and teaching points are often presented in these groups despite these differences. The resident can recommend alternate groups or locations (in-person or online), as members often vary significantly by location and meeting time. The resident also can make explicit that those with seemingly "more serious" problems often started like the patient, seeing their own issues as less problematic. Alternatively, the patient may feel they have already engaged in a similar program before and do not feel they will benefit again. It is important to discuss that SUD treatment is skill development and relapses are an indication of a need for further practice.

\section{Discussion}

The prevalence of SUDs and their co-occurrence with other psychiatric disorders makes it imperative that psychiatry residency training programs dedicate time and effort to treating them. Being adequately prepared to address reported barriers to engaging in SUD treatment can enhance the resident's ability to address these common challenging clinical situations. Positive experiences treating patients with SUDs early in residency training can strengthen the development of therapeutic skills needed to provide effective treatment to this patient population.

These therapeutic interventions require reflective and empathic listening consistent with MI style and approach to reinforce the therapeutic alliance. It is important to tailor the approach to the specific patient's needs and experiences. If the patient declines the treatment plan, the trainee should educate the patient about the risks of electing not to follow treatment recommendations, while continuing the therapeutic engagement by facilitating ongoing discussions of progress and reconsidering original recommendations at a specified time interval if ongoing adverse consequences of use continue. In these cases, it is important to outline specific harm reduction agreements (e.g., patient commits to avoid driving while intoxicated) paired with a contingency treatment plan should the patient's selected plan for treatment fail.

Commonly perceived barriers to outpatient SUD treatment present an opportunity for residents to make meaningful advances in treatment interventions. While these barriers have the potential to derail treatment, learning to anticipate and address them skillfully through empathic listening, accepting ambivalence, validation, and engagement in problem solving will result in increased comfort working with this population, ultimately improving care of this underserved population.
Funding Dr. Greenfield received support from the National Institute on Drug Abuse K24DA019855 and Dr. Hill received support from the National Institute on Drug Abuse K99/R00DA029115.

\section{Compliance with Ethical Standards}

Ethical Considerations This was not a research paper and no human subjects were involved; thus, an IRB was not obtained.

Disclosure On behalf of all authors, the corresponding author states that there is no conflict of interest.

\section{References}

1. Kelly TM, Daley DC. Integrated treatment of substance use and psychiatric disorders. Soc Work Public Health. 2013;28(3-4): 388-406. https://doi.org/10.1080/19371918.2013.774673.

2. Greenfield SF. Letter to the editor: training general psychiatrists to treat patients with substance use disorders: it is time to change the training requirements in psychiatry residency training. Am J Addict. 2019;28(3):150-2. https://doi.org/10.1111/ajad.12888.

3. Wu LT, McNeely J, Subramaniam GA, Brady KT, Sharma G, VanVeldhuisen P, et al. DSM-5 substance use disorders among adult primary care patients: results from a multisite study. Drug Alcohol Depend. 2017;179:42-6. https://doi.org/10.1016/j. drugalcdep.2017.05.048.

4. Isaacson JH, Fleming M, Kraus M, Kahn R, Mundt M. A national survey of training in substance use disorders in residency programs. J Stud Alcohol. 2000;61(6):912-5. https://doi.org/10.15288/jsa. 2000.61.912.

5. Renner JA Jr, Quinones J, Wilson A. Training psychiatrists to diagnose and treat substance abuse disorders. Curr Psychiatry Rep. 2005;7(5):352-9. https://doi.org/10.1007/s1 1920-005-0035-2.

6. Livingston JD, Milne T, Fang ML, Amari E. The effectiveness of interventions for reducing stigma related to substance use disorders: a systematic review. Addiction. 2012;107(1):39-50. https://doi.org/ 10.1111/j.1360-0443.2011.03601.

7. Imhof J, Hirsch R, Terenzi RE. Countertransferential and attitudinal considerations in the treatment of drug abuse and addiction. Int $\mathrm{J}$ Addict. 1983;18(4):491-510. https://doi.org/10.3109/ 10826088309033033.

8. Najavits LM, Griffin ML, Luborsky L, Frank A, Weiss RD, Liese BS, et al. Therapists' emotional reactions to substance abusers: a new questionnaire and initial findings. Psychother Theory Res Pract Train. 1995;32(4):669-77. https://doi.org/10.1037/0033-3204.32. 4.669.

9. van Boekel LC, Brouwers EP, van Weeghel J, Garretsen HF. Stigma among health professionals towards patients with substance use disorders and its consequences for healthcare delivery: systematic review. Drug Alcohol Depend. 2013;131(1-2):23-35. https:// doi.org/10.1016/j.drugalcdep.2013.02.018.

10. Miller WR, Rose GS. Toward a theory of motivational interviewing. Am Psychol. 2009;64(6):527-37. https://doi.org/10. 1037/a0016830.

11. Carroll KM, Ball SA, Nich C, Martino S, Frankforter TL, Farentinos C, et al. Motivational interviewing to improve treatment engagement and outcome in individuals seeking treatment for substance abuse: a multisite effectiveness study. Drug Alcohol Depend. 2006;81(3):301-12. https://doi.org/10.1016/j.drugalcdep. 2005.08.002.

12. American Psychiatric Association. Telepsychiatry and COVID-19. https://www.psychiatry.org/psychiatrists/practice/telepsychiatry/ 
blog/apa-resources-on-telepsychiatry-and-covid-19. Accessed Aug 262020.

13. Acevedo A, Garnick D, Ritter G, Lundgren L, Horgan C. Admissions to detoxification after treatment: does engagement make a difference? Subst Abus. 2016;37(2):364-71. https://doi. org/10.1080/08897077.2015.1080784.

14. Joe GW, Simpson DD, Broome KM. Retention and patient engagement models for different treatment modalities in DATOS. Drug Alcohol Depend. 1999;57(2):113-25.

15. McCartney G, Bouttell J, Craig N, Craig P, Graham L, Lakha F, et al. Explaining trends in alcohol-related harms in Scotland 19912011 (II): policy, social norms, the alcohol market, clinical changes and a synthesis. Public Health. 2016;132:24-32. https://doi.org/10. 1016/j.puhe.2015.12.012.

16. Boyle SC, LaBrie JW, Froidevaux NM, Witkovic YD. Different digital paths to the keg? How exposure to peers' alcohol-related social media content influences drinking among male and female first-year college students. Addict Behav. 2016;57:21-9. https:// doi.org/10.1016/j.addbeh.2016.01.011.

17. Carrus G, Panno A, Deiana L, et al. Group membership and adolescents' alcohol intake: the role of drinking motives. J Stud Alcohol Drugs. 2016;77(1):143-9. https://doi.org/10.15288/jsad. 2016.77.143

18. Chambers RA, Wallingford SC. On mourning and recovery: integrating stages of grief and change toward a neuroscience-based model of attachment adaptation in addiction treatment. Psychodyn Psychiatry. 2017;45(4):451-73. https://doi.org/10.1521/pdps.2017. 45.4.451.

19. National Institute on Alcohol Abuse and Alcoholism. National Institutes of Health. Building your drink refusal skills. https://
www.rethinkingdrinking.niaaa.nih.gov/tools/Interactiveworksheets-and-more/Stay-in-control/drink-Refusal-Skills.aspx Accessed 26 Aug 2020.

20. Dennis ML, Foss MA, Scott CK. An eight-year perspective on the relationship between the duration of abstinence and other aspects of recovery. Eval Rev. 2007;31(6):585-612. https://doi.org/10.1177/ 0193841 X07307771.

21. Lee J, Kresina TF, Campopiano M, Lubran R, Clark HW. Use of pharmacotherapies in the treatment of alcohol use disorders and opioid dependence in primary care. Biomed Res Int. 2015;2015: 137020-11. https://doi.org/10.1155/2015/137020.

22. McLellan AT, Lewis DC, O'Brien CP, Kleber HD. Drug dependence, a chronic medical illness: implications for treatment, insurance, and outcomes evaluation. JAMA. 2000;284(13):1689-95. https://doi.org/10.1001/jama.284.13.1689.

23. Pétursson $\mathrm{H}$. The benzodiazepine withdrawal syndrome. Addiction. 1994;89(11):1455-9. https://doi.org/10.1111/j.1360-0443.1994. tb03743.x.

24. Budney AJ, Hughes JR. The cannabis withdrawal syndrome. Curr Opin Psychiatry. 2006;19(3):233-8. https://doi.org/10.1097/01. yco.0000218592.00689.e5.

25. Nunes EV, Levin FR. Treatment of depression in patients with alcohol or other drug dependence: a meta-analysis. JAMA. 2004;291(15):1887-96. https://doi.org/10.1001/jama.291.15.1887.

Publisher's Note Springer Nature remains neutral with regard to jurisdictional claims in published maps and institutional affiliations. 